\title{
Use of Fourier transform near infrared spectroscopy for the detection of residues from wood processing industry in the pellet sector
}

\author{
M. Mancini, ${ }^{a^{*}} \AA$ A. Rinnan, ${ }^{\mathrm{b}}$ A. Pizzi ${ }^{\mathrm{a}}$ and G. Toscano
}

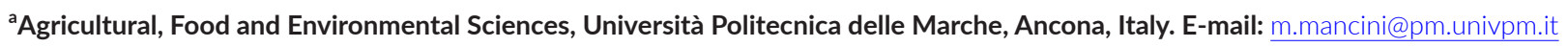

bDepartment of Food Science, University of Copenhagen, Copenhagen, Denmark

\begin{abstract}
With the aim to reduce the dependence on fossil fuels and mitigate climate change, biomass for energy use is becoming more and more important. In particular, wood pellets are gaining greater attention because of the easy logistics and their high energy density in comparison to other solid biomasses. This is also demonstrated by the rapid growth of its demand in Europe. For pellets, traceability is a very important and complex issue, since the feedstock employed is de-structured by grinding and densification and thus losing qualitative information. As a consequence, a multitude of wood sources can participate to their blend in a concealed way, modifying the quality. The international standard EN ISO 17225-2 defines different quality classes for woody pellets taking into consideration chemical-physical parameters and the provenance traceability and composition of the material. In particular, the European standard considers the possibility of using by-products and residues from the wood processing industry, i.e. wood containing glue residues, for pellet production, but Italian national legislation considered these materials like waste. This work aimed at verifying the ability of Fourier Transform-Near-Infrared (FT-NIR) spectroscopy to discriminate between treated and virgin wood. For this purpose, more than one hundred samples of virgin and treated wood deriving from the wood processing industry were collected and analyzed by FT-NIR. The results obtained showed that this technique is able to provide qualitative information about pellet traceability. Therefore, the methodology should be considered as a valid tool for pellet quality control, because it allows to obtain information about the origin of the material used for its production.
\end{abstract}

\section{Introduction}

During the last years the use of biomass is gaining greater attention because of the climate changes caused by fossil fuel combustion. ${ }^{1}$ As a consequence, European current policies promote the production of bioenergy and, in this context, an important role could be played by pellets. In fact, compared to other types of woody biomass, pellets are one of the most interesting due to the higher energy density, the durability and the advantages in terms of transportation and storage costs. In Europe, the market for pellets is increasing. In particular wood pellet consumption amounts to 18.8 million tons and is expected to reach 50 million tons by 2020 according to the European Biomass Association. $^{2}$
Considering the rapid growth of the pellet market, it is very important to analyze the product quality, as it has strong implications for environmental, technical and economic aspects. ${ }^{3}$ Moreover, one has to consider the fact that with the increased demands for pellets, other different raw materials can be used to make up pellets apart from wood biomass, making its traceability particularly complex. In fact, different materials can participate to the blend in a concealed way, causing unpleasant effects and influencing combustion behavior and emissions produced.

EN ISO 17225-2 standards establish the quality of woody pellets, indicating specific limits of chemical-physical parameters and defining attributes like the origin and source of the

\section{(C) 2019 The Authors}

This licence permits you to use, share, copy and redistribute the paper in any medium or any format provided that a full citation to the original paper is given, the use is not for commercial purposes and the paper is not changed in any way. 
material. Pellets are classified in three quality classes: A1, $\mathrm{A} 2$ and $\mathrm{B}$. In terms of the origin and source of the material, one of the differences between $\mathrm{A} 1 / \mathrm{A} 2$ and $\mathrm{B}$ quality classes is the possibility to use by-products and residues from the wood processing industry, making the traceability of the pellets relevant. Moreover, the standard considers the possibility of using treated material, i.e. wood containing painting or glue residues, for pellets production, but its use as fuel is not allowed in some EU countries (such as Italy, according to D.Igs. n. 152/2006).

The great weakness is that no methodologies to check the origin and source of the material are provided by the technical standard. Moreover, traditional analyses are very time consuming, complex and expensive, and not in line with the real need of the market and with the economic return of the sector. A valid solution could be offered by near infrared spectroscopy (NIRS). This analytical technique is fast, cheap and non-invasive, and might provide information about pellet quality, answering the request about the origin and source of the material required by the technical standards.

The main aim of this study was to verify the possibility to use NIRS for discriminating between virgin wood and treated wood. For this purpose, more than one hundred samples have been collected and subsequently analyzed by FT-NIR Spectroscopy coupled with chemometrics. In particular, Principal Component Analysis (PCA) was applied as an unsupervised technique to explore the spectral information and Partial Least Square Discriminant Analysis (PLS-DA) as a classification technique. Sensitivity and specificity values were considered to evaluate the classification performance of the model.

\section{Materials and methods \\ Sample collection and preparation}

The study was conducted using 106 samples from four different types of residues from wood processing industry-glue-laminated wood, plywood, oriented strand board (OSB) and chipboard-as well as virgin wood (Table 1). The samples were collected from different sawmills of the region and could be considered representative of the national scene, since most of the wood composites materials on the market are imported from abroad. The residues from the wood processing industry were collected as beams or boards, while virgin wood was collected as whole pieces of wood as tree log disks wood
Table 1. Dataset of treated and virgin samples.

\begin{tabular}{|l|c|}
\hline & Number \\
\hline Virgin fir & 13 \\
\hline Virgin pine & 10 \\
\hline Virgin beech & 16 \\
\hline $\begin{array}{l}\text { Glue laminated hardwood (ash, } \\
\text { sessile oak) }\end{array}$ & 10 \\
\hline Glue laminated softwood (pine) & 16 \\
\hline Plywood & 14 \\
\hline Oriented Strand Board (OSB) & 16 \\
\hline Chipboard & 11 \\
\hline Total & 106 \\
\hline
\end{tabular}

slices, beams or boards. Regarding virgin wood, only the three most common European species for the energy pellet sector, i.e. fir, pine and beech, have been taken into consideration.

First of all, the samples were chopped in smaller pieces to simplify the subsequent procedure of grinding. A cutting mill (mod. SM 2000, RETSCH) was used to grind the material below $1 \mathrm{~mm}$ of particle size. The samples were stored in plastic containers and analyzed by FT-NIR spectroscopy.

The moisture content between the samples was similar, as the wood slices were conditioned at $45^{\circ} \mathrm{C}$ for $24 \mathrm{~h}$ before grinding.

Two types of glues-vinyl and polyurethane glue-have also been collected. It is important to take into consideration that these are not the resin-binder systems normally used in the wood processing industry and have only been analyzed for interpretation purposes. The glues used in the industry is phenol-formaldehyde, urea-formaldehyde, melamine-formaldehyde and isocyanate, ${ }^{4}$ but it is assumed that the NIRS spectra are similar between the different glues.

\section{Near-infrared spectroscopy}

The set of 106 samples were analyzed using a FT-NIR spectrophotometer (mod. Nicolet iS 10, Thermo) equipped with a diffuse reflectance accessory (mod. Smart Near-IR upDRIFT, Thermo). The following settings were used: 64 scans per sample; spectral resolution of $4 \mathrm{~cm}^{-1}$; wavenumber range from $10,000 \mathrm{~cm}^{-1}$ to $4000 \mathrm{~cm}^{-1}$.

A total of three measurements have been recorded on each sample. All measurements have been performed at room temperature $\left(18-20^{\circ} \mathrm{C}\right)$. To exclude the signals not associated with the sample, but with the instrument or 
environment, a blank spectrum was acquired every hour, and the recorded spectra were corrected accordingly.

\section{Data processing and multivariate data analysis}

The signal of the spectra collected were pre-processed in order to minimize the effect of baseline shifts and noise and increase the performance of the subsequent classification model. ${ }^{5}$ In order to reduce the light scattering, a second spectral derivative (Savitzky-Golay ${ }^{6}$ with 21 smoothing points and $2^{\text {nd }}$ order polynomial) was applied.

The PCA technique has been used as an exploratory analysis of the spectral data in order to explore the overall statistical variance, detect for outliers and search for clusters in the samples on the basis of chemical differences between treated and virgin wood samples. The loading plot of the PCA was investigated with the aim to identify the compounds responsible for the discrimination between the different types of material.

Successively, PLS-DA7,8 was applied for classification purposes. In order to evaluate the performance of the model the dataset was split into a calibration and a test set using the Kennard-Stone algorithm. ${ }^{9}$ PLS-DA calibration model was validated using Venetian blind-cross validation (5 segments). Subsequently, the external test set was used to validate the classification model and predict the new samples. The quality parameters for PLS-DA model was evaluated by sensitivity and specificity values.

All computation included in this study were performed in Matlab (ver. 7.10.0, The MathWorks, Natwick, USA) using in-house functions based on existing algorithms.

\section{Results and discussion Spectral analysis}

Near-infrared spectra were pre-treated using second derivative with 21 smoothing points. Even if each spectrum has been computed as an average of 64 successive scans to increase the signal to noise ratio, the range from $10,000 \mathrm{~cm}^{-1}$ to $7700 \mathrm{~cm}^{-1}$ remains noisy and it has been removed from the subsequent analysis.

Figure 1 shows the $2^{\text {nd }}$ derivatives of the averaged FT-NIR spectra of all virgin wood and chipboard samples. The spectral differences between these two materials are particularly highlighted since chipboard is the wood composite material with the higher percentage of glue. The two lines denote some differences because of the varying chemical composition of the samples. The dotted lines in Figure 1 could be used to support the interpretation of the FT-NIR spectra.

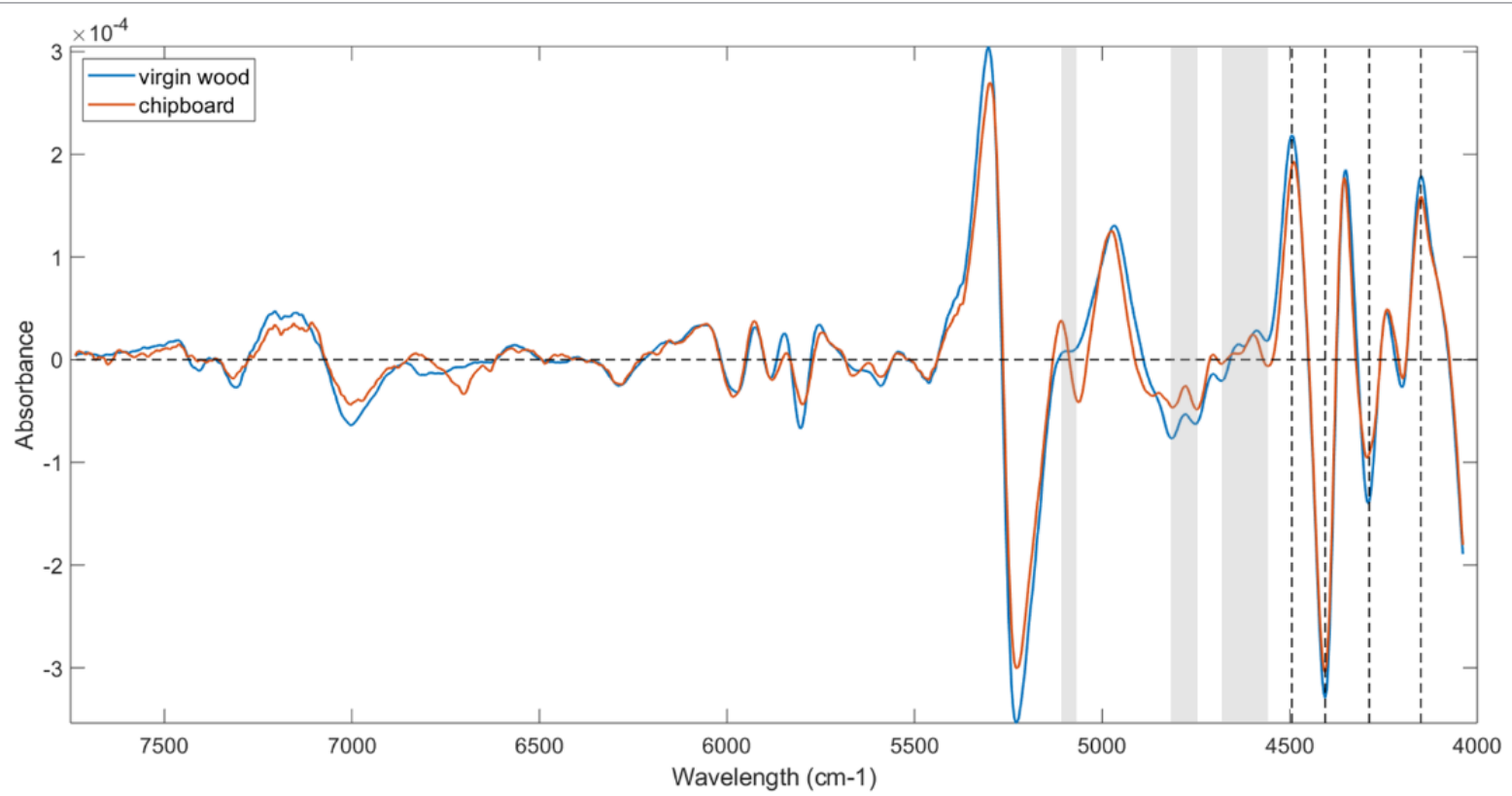

Figure 1. $2^{\text {nd }}$ derivative (Savitzky-Golay using a window size of 21 and a $2^{\text {nd }}$ order polynomial) of the averaged FT-NIR spectra of virgin wood and chipboard samples (wood samples: blue line, chipboard samples: orange line). The gray areas refer to relevant spectral differences. 
The chipboard mean spectrum is quite similar to the virgin wood spectrum apart from some slight differences in the regions marked in gray: (i) from $4550 \mathrm{~cm}^{-1}$ to $4875 \mathrm{~cm}^{-1}$ and (ii) from $5000 \mathrm{~cm}^{-1}$ to $5130 \mathrm{~cm}^{-1}$. These regions are related to $\mathrm{N}$-bonds of the glue present in the treated wood.

Some other differences can be noticed between the two spectra. The differences in the intensity of the peaks at $4494,4405,4288$ and $4150 \mathrm{~cm}^{-1}$ are mostly linked to $\mathrm{C}-\mathrm{H}$ bonds, in fact the compounds of wood, such as lignin and holocellulose, have a higher number of these bonds in comparison to treated wood.

\section{PCA}

PCA analysis was performed on the pretreated data matrix in order to investigate for clustering in the data and explore the overall variance. By looking at the PCA score plot (Figure 2) it is possible to observe clustering or separation trends. Chipboard and plywood samples are well grouped and separated from virgin wood, while OSB is also separated from virgin wood, but scattered in the score plot. OSB is an engineered wood used for a wide variety of purposes, including interior and structural application. On the basis of the application, the strands are bonded together with different types and quantities of glue, influencing the distribution in the plot. Generally, when the material is used for interior application, strands are bound with urea-formaldehyde glue, the same product applied also for chipboard. Moreover, OSB could be made up by hardwood and/or softwood strands explaining the location of the samples into the plot.

Glue-laminated wood and virgin wood are not so well separated, but they are well grouped on the basis of hardwood and softwood samples along PC1: hardwood samples have negative PC1 scores whereas softwood samples have positive PC1 scores. The loadings were investigated to figure out which variables, and associated compounds, are responsible for the separation of the samples into the different clusters. The most relevant wavenumbers are reported in Table 2 .

The most relevant wavenumbers assigned to glue compounds were reported also in Figure 4. The plot shows the mean spectrum of virgin wood samples and the spectrum of vinyl and polyurethane glue.

It can be noticed that almost all the wavelengths assigned to glue correspond to peaks in the vinyl and polyurethane spectra. Some wavelengths assigned to wood correspond also to peaks in the two glue spectra. This is probably due to the fact that the glues analyzed are not the ones normally used in the wood processing industry sector. Moreover, the adhesives are normally consolidated with the wood particles with heat and/or pressure process ${ }^{4}$ changing the structure of the final product. However, in this study, the glue has been analyzed as-is apart from the drying and polymerization process.

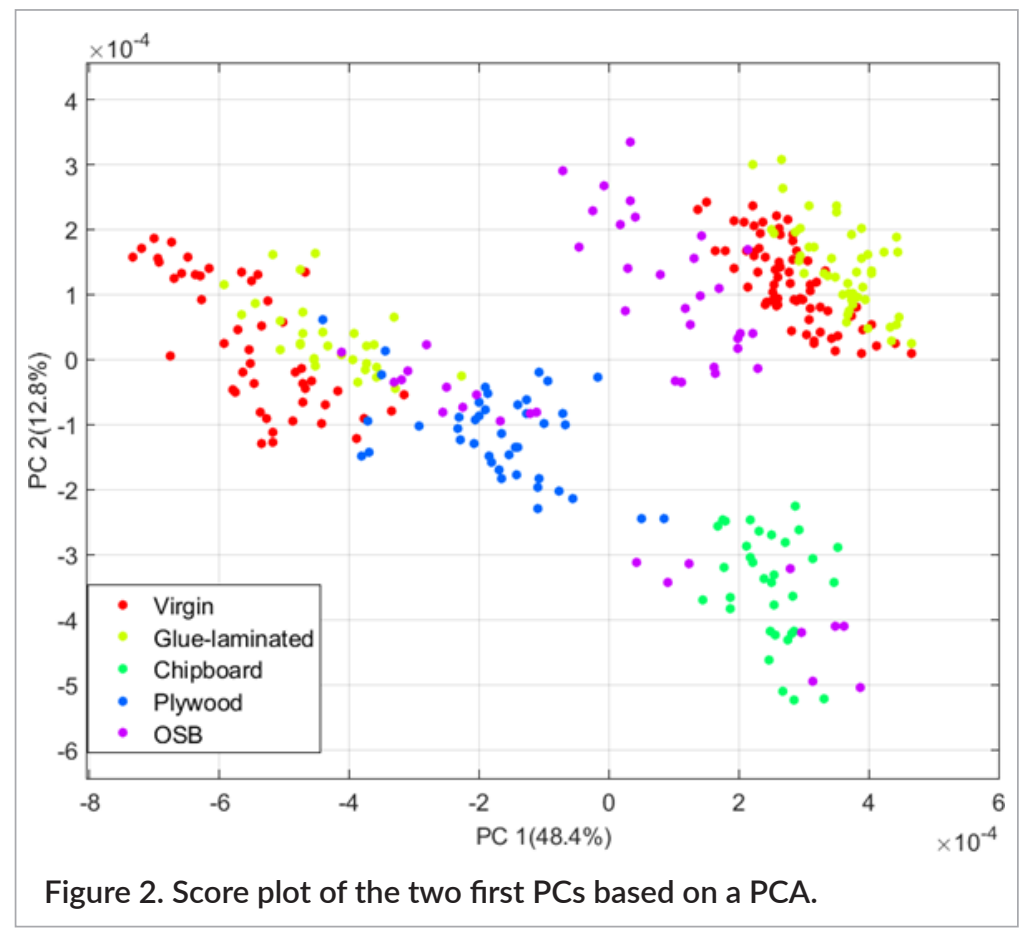




\section{PLS-DA}

PLS-DA was applied to classify virgin wood from treated wood, i.e. glue-laminated wood, plywood, OSB and chipboard. The model was developed on the data matrix pre- treated using second derivative with 21 smoothing points and removing the part of the spectrum from $10,000 \mathrm{~cm}^{-1}$ to $7700 \mathrm{~cm}^{-1}$.

Table 2. Band assignment of FT-NIR spectra associated with the main spectral differences between treated and untreated wood. The first column refers to numbers associated with spectral differences highlighted in Figure 3. (str.: stretching; bend.: bending; def.: deformation; OT: overtone; L: lignin; H: hemicellulose; C: cellulose).

\begin{tabular}{|c|c|c|c|c|c|}
\hline \multirow[b]{2}{*}{$N^{\circ}$} & \multicolumn{2}{|c|}{ Wavenumber $\left(\mathrm{cm}^{-1}\right)$} & \multirow[b]{2}{*}{ Assignment } & \multirow[b]{2}{*}{ Compound } & \multirow[b]{2}{*}{ Ref. } \\
\hline & Measured & Bibliography & & & \\
\hline 11 & 7024 & 7003 & $1^{\text {st }} \mathrm{OT} \mathrm{O}-\mathrm{H}$ str. $+\mathrm{H}_{2} \mathrm{O}(\mathrm{C}$, water $)$ & wood & 10 \\
\hline 12 & 6815 & 6802 & $\begin{array}{l}\text { combination modes of } \mathrm{N}-\mathrm{H} \\
\text { streches }\end{array}$ & glue & 11 \\
\hline 13 & 6700 & $\approx 6700$ & $1^{\text {st }}$ OT O-H str. $(\mathrm{H})$ & wood & 10 \\
\hline $1-14$ & 5978 & 5978 & $1^{\text {st }}$ OT $\mathrm{C}_{\mathrm{ar}}-\mathrm{H}$ str. $(\mathrm{L})$ & wood & 10 \\
\hline \multirow[t]{2}{*}{$2-15$} & 5940 & 5950 & $1^{\text {st }}$ OT C-H str. $(H)$ & wood & 10 \\
\hline & & 5935 & $1^{\text {st }}$ OT $C_{a r}-H$ str. (L) & wood & 10 \\
\hline \multirow[t]{3}{*}{3} & 5805 & 5810 & methyl $\mathrm{C}-\mathrm{H}$ bond & glue & 12,13 \\
\hline & & $5600-6000$ & $\begin{array}{l}1^{\text {st }} \mathrm{OT} \mathrm{C}-\mathrm{H} \text { str. of methyl and } \\
\text { methylene structures }\end{array}$ & glue & 11,12 \\
\hline & & 5800 & $1^{\text {st }}$ OT C-H str. $(H)$ & wood & 10 \\
\hline 16 & 5770 & 5776 & $1^{\text {st }}$ OT C-H str. (C) & wood & 10 \\
\hline 17 & 5331 & 5333 & $2^{\text {nd }} \mathrm{OT} \mathrm{C}=\mathrm{O}$ str. $(\mathrm{C})$ & wood & 14 \\
\hline 4 & 5311 & 5313 & $\mathrm{C}-\mathrm{H}$ OT of aldehyde groups & glue & 13 \\
\hline \multirow[t]{2}{*}{18} & 5257 & 5257 & $1^{\text {st }}$ OT-CN functional group & glue & 12 \\
\hline & & 5245 & $2^{\text {nd }} \mathrm{OT} \mathrm{C}=\mathrm{O}$ str. $(\mathrm{H})$ & wood & 10 \\
\hline 5 & 5242 & 5257 & $1^{\text {st }}$ OT-CN functional group & glue & 12 \\
\hline 19 & 5061 & 5051 & $\mathrm{O}-\mathrm{H}$ str. $+\mathrm{O}-\mathrm{H}$ def. of $\mathrm{H}_{2} \mathrm{O}$ (water) & wood & 10 \\
\hline 20 & 4910 & 4904 & $\mathrm{CH}$ deformation and $\mathrm{OH}$ str. $(\mathrm{C}, \mathrm{L})$ & wood & 15 \\
\hline 6 & 4636 & 4645 & $\begin{array}{l}\text { Combination modes between the } \\
\mathrm{N}-\mathrm{H} \text { stretches }\end{array}$ & glue & 11 \\
\hline 21 & 4536 & 4549 & $\begin{array}{l}\text { Combination modes between the } \\
\mathrm{N}-\mathrm{H} \text { stretches }\end{array}$ & glue & 11 \\
\hline 7 & 4505 & & Holocellulose $(\mathrm{C}, \mathrm{H})$ & wood & 16 \\
\hline \multirow[t]{4}{*}{$8-22$} & 4440 & 4449 & $\mathrm{C}-\mathrm{H}_{2}$ str. + bend. combination & glue & 11 \\
\hline & & 4450 & $\mathrm{CH}_{2}$ combination of methylol group & glue & 17 \\
\hline & & $4970-4250$ & strong- $\mathrm{NH}_{2}$ combination & glue & 17 \\
\hline & & $4200-4800$ & $\begin{array}{l}\mathrm{N}-\mathrm{H} \text { and } \mathrm{C}-\mathrm{H} \text { combination } \\
\text { vibrations }\end{array}$ & glue & 11 \\
\hline 23 & 4382 & 4392 & $\begin{array}{l}\mathrm{O}-\mathrm{H} \text { str. + C-C str. and/or C-H str. } \\
+\mathrm{C}-\mathrm{H} \text { def. (C) }\end{array}$ & wood & 10 \\
\hline 9 & 4359 & 4365 & $\begin{array}{l}\mathrm{C}-\mathrm{O} \text { str. }+\mathrm{O}-\mathrm{H} \text { str. or } \mathrm{C}-\mathrm{H}_{2} \text { bend. } \\
+\mathrm{C}-\mathrm{H}_{2} \text { str. }(\mathrm{C})\end{array}$ & wood & 10 \\
\hline 24 & 4324 & & Holocellulose $(\mathrm{C}, \mathrm{H})$ & wood & 16 \\
\hline $10-25$ & 4289 & 4288 & $\mathrm{CH}$ str. + $\mathrm{C}-\mathrm{H}$ def. $(\mathrm{H})$ & wood & 10 \\
\hline
\end{tabular}



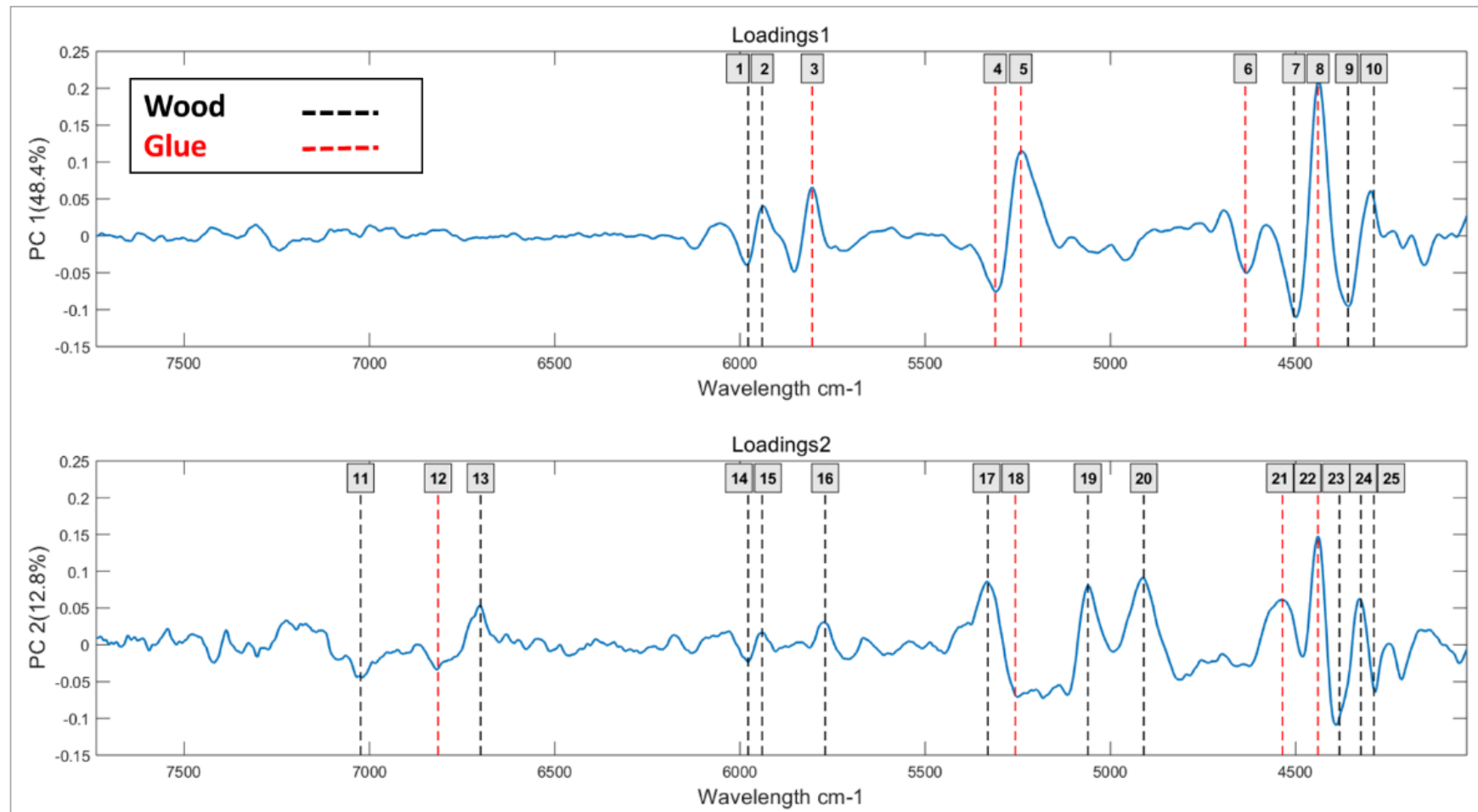

Figure 3. First two PCA loadings. Important wavenumbers for discrimination between treated and untreated wood samples are marked with red (glue) and black (wood) dotted lines.

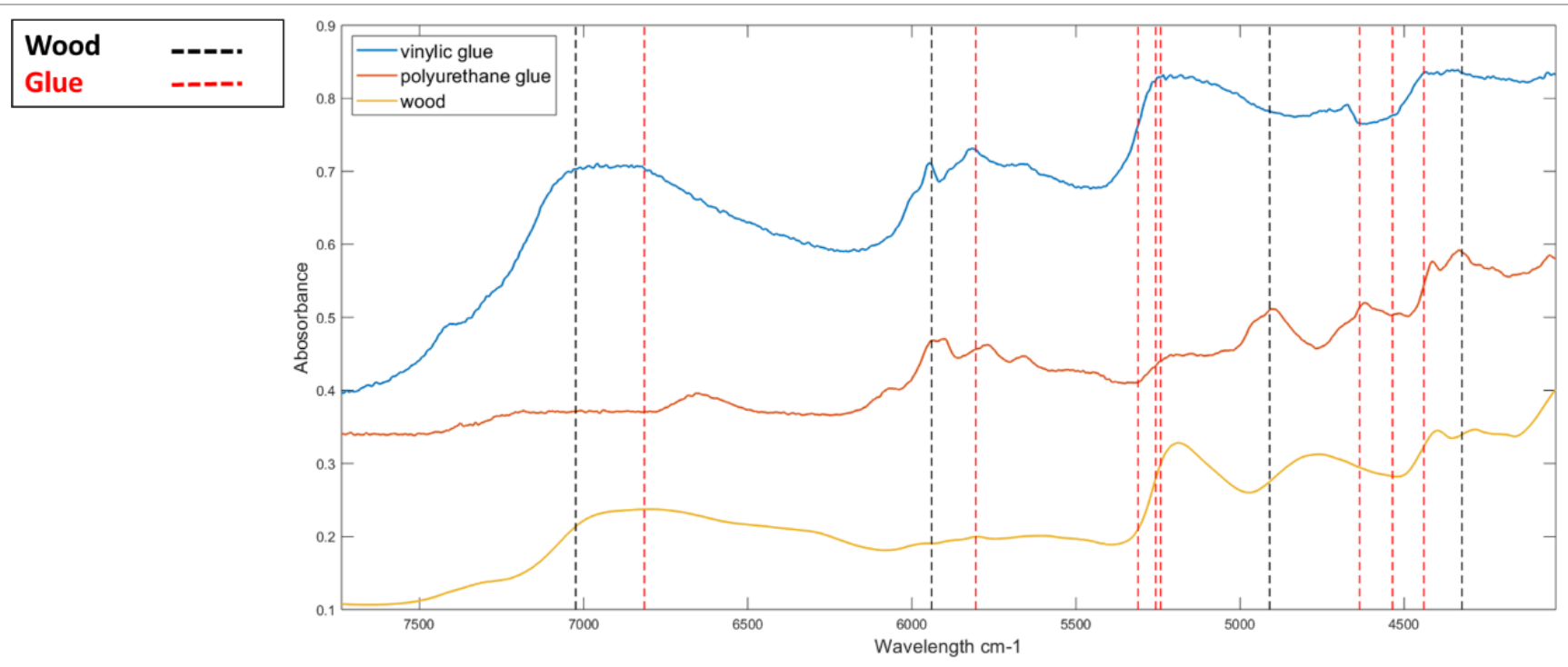

Figure 4. Plot of the mean spectrum of virgin wood samples and of vinyl and polyurethane glue spectra.

The training set of the model was built with 74 samples and 32 samples were used in the test set. A total of 5 latent variables (LVs) were needed to develop the classification model accounting for $71.87 \%$ of explained variance in $X$ matrix and $78.84 \%$ of variance in the $y$ vector. The model had a total misclassification rate of $10.4 \%$ and present a high correlation, $\mathrm{R}^{2}=1.00$.
Sensitivity and specificity values were used to evaluate the classification performance of the PLS-DA model. The sensitivity value suggests the ability to correctly classify the samples belonging to a specific class and the specificity value the ability to reject the samples of all the other classes. Both parameters were calculated for the training and test sets and good results were obtained: $95 \%$ of 

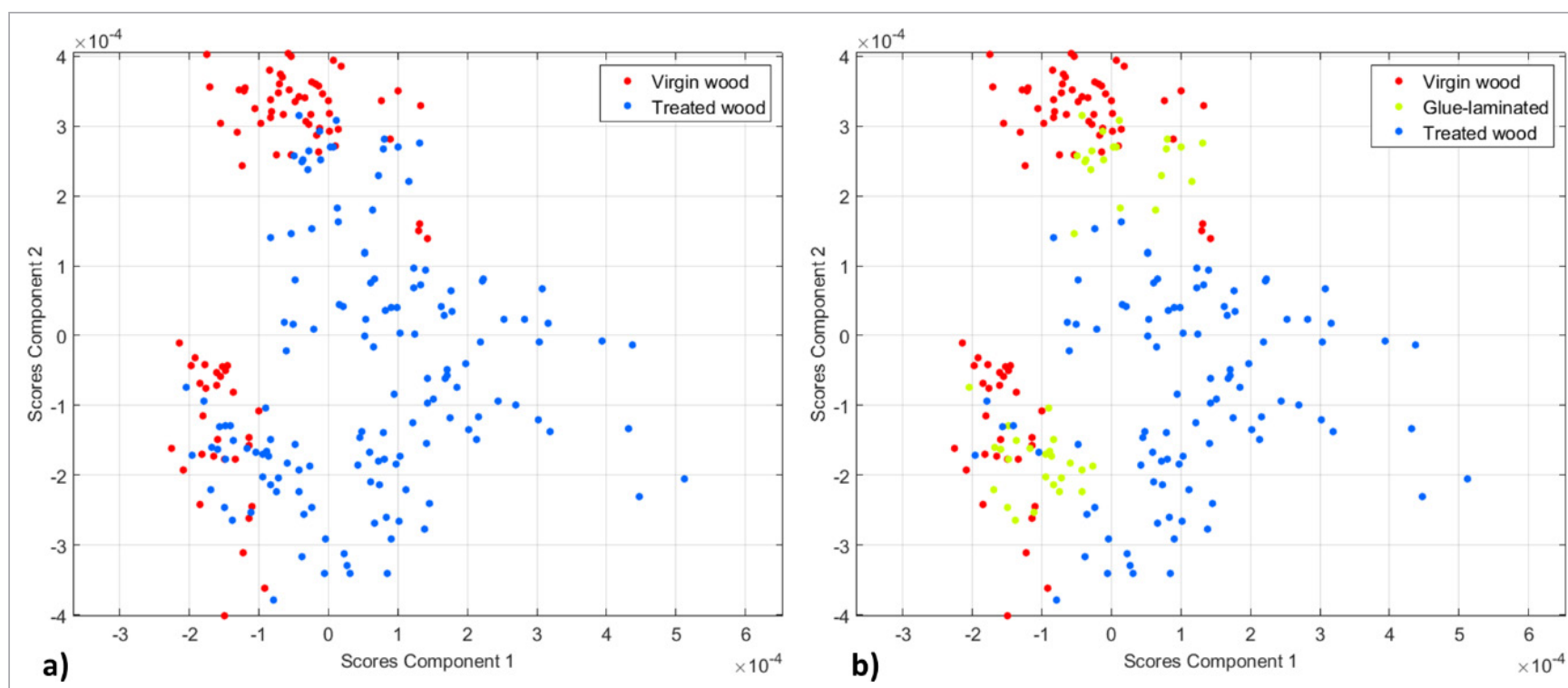

Figure 5. PLS-DA score plot of the two first LVs colored in accordance to treated and virgin wood (a) and treated, gluelaminated and virgin wood (b).

sensitivity and $80.2 \%$ of specificity for training set and $95 \%$ of sensitivity and $86.1 \%$ of specificity for test set.

As also showed in the PLS-DA score plot (Figure 4a), the model was able to discriminate between treated and untreated wood samples, but the separation was mainly due to hardwood and softwood samples. Softwood has positive values on LV2 and hardwood has negative values on LV2. This is to be related to the fact that gluelaminated wood has a low percentage of glue and, as a consequence, the position of these samples on the score plot is very close to virgin wood (Figure 4b).

For this reason, it is important to take into consideration that the classification performance could increase splitting the data matrix and considering only virgin wood and glue-laminated wood in a specific classification model and all the other treated samples and virgin wood in another model.

\section{Conclusion}

In this study, a classification model for the detection of wood-based composite materials in the pellet sector was developed using FT-NIR spectroscopy coupled with chemometrics. The sensibility and sensitivity values of the PLS-DA model suggest that it could be used for screening classification purposes. Furthermore, the clustering in the PLS-DA score plot suggests that building a specific model for classifying glue-laminated/virgin wood and all the other treated samples/virgin wood could increase the classification performance.

Being rapid, cheap and non-invasive, the FT-NIR spectroscopy technique is suitable for being the first methodology able to provide rapid responses about pellet traceability, answering in this way the question of EN ISO 17225-2 about the origin and source of the pellets. Moreover, FT-NIR spectroscopy is a valid pre-screening tool for analyzing large volumes of biomass, overcoming the sampling problem and allowing a total quality control if used for industrial in-line applications.

\section{References}

1. S.V. Vassilev, D. Baxter, L.K. Andersen and C.G. Vassileva, "An overview of the chemical composition of biomass," Fuel 89, 913-933 (2010). https:// doi.org/10.1016/j.fuel.2009.10.022

2. AEBIOM-European Bioenergy Outlook 2013, Statistical Report. Last access: http://www.aebiom. org/blog/aebiom-statistical-report-2013 (2013)

3. G. Toscano, G. Riva, E. Foppa Pedretti, F. Corinaldesi, C. Mengarelli and D. Duca, "Investigation on wood pellet quality and relationship between ash content and the most important chemical elements", 
Biomass Bioenerg. 56, 317-322 (2013). https://doi. org/10.1016/j.biombioe.2013.05.012

4. N.M. Stark, Z. Cai and C. Carll, "Wood-based composite materials: panel products, glued-laminated timber, structural composite lumber, and woodnonwood composite materials", in Wood Handbook: Wood as an Engineering Material, Centennial Edn. General technical report FPL; GTR-190. U.S. Dept. of Agriculture, Forest Service, Forest Products Laboratory, Madison, WI, Ch. 11, pp. 11.1-11.28 (2010).

5. Å. Rinnan, F.v.d. Berg and S.B. Engelsen, "Review of the most common pre-processing techniques for near-infrared spectra", TrAC Trends Anal. Chem. 28, 1201-1222 (2009). https://doi.org/10.1016/j. trac.2009.07.007

6. A. Savitzky and M.J.E. Golay, "Smoothing and differentiation of data by simplified least squares procedures", Anal. Chem. 36, 1627-1639 (1964). https:// doi.org/10.1021/ac60214a047

7. S. Wold, M. Sjöström and L. Eriksson, "PLSregression: a basic tool of chemometrics", Chemometr. Intell. Lab. Syst. 58, 109-130 (2001). https://doi.org/10.1016/S0169-7439(01)00155-1

8. M. Barker and W. Rayens, "Partial least squares for discrimination", J. Chemometr. 17, 166-173 (2003). https://doi.org/10.1002/cem.785

9. R.W. Kennard and L.A. Stone, "Computer aided design of experiments", Technometrics 11, 137-148 (1969). https://doi.org/10.1080/00401706.1969.104 90666

10. M. Schwanninger, J. Rodrigues and K. Fackler, "A review of band assignments in near infrared spectra of wood and wood components", J. Near Infrared Spectrosc. 19, 287-308 (2011). https://doi. org/10.1255/jnirs.955
11. E. Minopoulou, E. Dessipri, G.D. Chryssikos, V. Gionis, A. Paipetis and C. Panayiotou, "Use of NIR for structural characterization of urea-formaldehyde resins", Int. J. Adhes. Adhes. 23, 473-484 (2003). https://doi.org/10.1016/S0143-7496(03)00089-7

12. S.K. Tomlinson, O.R. Ghita, R.M. Hooper and K.E. Evans, "The use of near-infrared spectroscopy for the cure monitoring of an ethyl cyanoacrylate adhesive", Vibr. Spectrosc. 40, 133-141 (2006). https://doi.org/10.1016/j.vibspec.2005.07.009

13. Y. Dwivedi and S.B. Rai, "Spectroscopic study of overtone and combination bands in aliphatic aldehydes", Vibr. Spectrosc. 49, 278-283 (2009). https:// doi.org/10.1016/j.vibspec.2008.10.009

14. J. Yan, N. Villarreal and B. Xu, "Characterization of degradation of cotton cellulosic fibers through near infrared spectroscopy", J. Polym. Environ. 21, 902-909 (2013). https://doi.org/10.1007/s10924013-0605-z

15. C.-M. Popescu and M.-C. Popescu, "A near infrared spectroscopic study of the structural modifications of lime (Tilia cordata Mill.) wood during hydro-thermal treatment", Spectrochim. Acta A 115, 227-233 (2013). https://doi.org/10.1016/j.saa.2013.06.002

16. E. Pecoraro, B. Pizzo, A. Alves, N. Macchioni and J.C. Rodrigues, "Measuring the chemical composition of waterlogged decayed wood by near infrared spectroscopy", Microchem. J. 122, 176-188 (2015). https://doi.org/10.1016/j.microc.2015.05.005

17. E. Dessipri, E. Minopoulou, G.D. Chryssikos, V. Gionis, A. Paipetis, and C. Panayiotou, "Use of FT-NIR spectroscopy for on-line monitoring of formaldehyde-based resin synthesis", Eur. Polym. J. 39, 1533-1540 (2003). https://doi.org/10.1016/ S0014-3057(03)00073-9 